\title{
Preparation and luminescent properties of Eu-doped transparent mica glass-ceramics
}

Author's Name

\author{
Seiichi TARUTA*, Mutsumi MATSUKI, \\ ${ }^{\dagger}$ Hiromasa NISHIKIORI, ${ }^{\dagger \dagger}$ Tomohiko YAMAKAMI, \\ Tomohiro YAMAGUCHI and Kunio KITAJIMA
}

Author's Affiliation

Department of Chemistry and Materials Engineering, Faculty of Engineering, Shinshu University, 4-17-1, Wakasato, Nagano-shi, Nagano, 380-8553, Japan

†Department of Environmental Science and Technology, Faculty of Engineering, Shinshu University,

4-17-1, Wakasato, Nagano-shi, Nagano, 380-8553, Japan

${ }^{\dagger}$ Technical Division, Faculty of Engineering, Shinshu University, 4-17-1, Wakasato, Nagano-shi, Nagano, 380-8553, Japan

\section{*Corresponding Author}

Seiichi TARUTA

Department of Chemistry and Materials Engineering, Faculty of Engineering, Shinshu University,

4-17-1, Wakasato, Nagano-shi, Nagano, 380-8553, Japan

TEL: +81-26-269-5416

FAX: +81-26-269-5424

E-mail: staruta@shinshu-u.ac.jp 


\begin{abstract}
Eu-doped transparent mica glass-ceramics were prepared, the influence of Eu -doping on the crystallization of the parent glasses was investigated and the luminescent properties of the parent glasses and the glass-ceramics were estimated. A small additive amount of Eu element was very effective in preparing transparent mica glass-ceramics. However, the excess addition led to the coarsening of phase separation in the glass phase and the separation of unidentified crystal phases and $\beta$-eucryptite during heating of the parent glasses, which caused white opaque at lower heating temperatures. When mica crystals were separated, Eu ions entered the interlayers of mica crystals. The observed emission and excitation spectra showed that parts of $\mathrm{Eu}^{3+}$ ions which were added as $\mathrm{Eu}_{2} \mathrm{O}_{3}$ were reduced to $\mathrm{Eu}^{2+}$ ions during melting of the starting materials and heating the parent glasses in air and the energy transfer from $\mathrm{Eu}^{2+}$ to $\mathrm{Eu}^{3+}$ ions occurred.
\end{abstract}

Keyword: Optical properties; Glass; Glass ceramics; Silicate 


\section{Introduction}

Europium ions $\left(\mathrm{Eu}^{2+}\right.$ and $\left.\mathrm{Eu}^{3+}\right)$ are well known as activators in phosphors. The $\mathrm{Eu}^{2+}$-doped phosphors emit blue light, which originated in $4 \mathrm{f}^{6} 5 \mathrm{~d} \rightarrow 4 \mathrm{f}^{7}$ transition of $\mathrm{Eu}^{2+}$ ions and the $\mathrm{Eu}^{3+}$-doped phosphors emit red light, which originated in ${ }^{5} \mathrm{D}_{0} \rightarrow{ }^{7} \mathrm{~F}_{\mathrm{J}}$ transition of $\mathrm{Eu}^{3+}$ ions. For example, $\mathrm{BaMgAl}_{10} \mathrm{O}_{17}: \mathrm{Eu}^{2+}$ and $(\mathrm{Y}, \mathrm{Gd}) \mathrm{BO}_{3}: \mathrm{Eu}^{3+}$ are used as blue and red phosphors, respectively, for plasma display panels. So such phosphors activated with europium ions have been widely used in other commercial applications and also have been investigated.

Transparent glass-ceramics are interesting hosts for phosphors used for white light emitting diodes, laser materials and so on. Fluoride crystals and glasses are desirable hosts for optically active rare-earth cations because of their low phonon energies and broad transparency in the infrared region of spectrum used for amplification of light in telecommunications systems [1]. And transparent oxyfluoride glass-ceramics, based on fluoride crystals dispersed throughout a continuous silicate glass, have been shown to combine the optical advantages of rare-earth-doped fluoride crystals with the ease of forming and handling of conventional oxide glasses [1]. On the other hand, we succeeded in preparing novel transparent and machinable mica glass-ceramics from oxyfluoride glasses $[2,3]$. The separated fluorine-micas had size of $<50 \mathrm{~nm}$ and their interlayer cations were lithium ions. The transparent fluorine-mica glass-ceramics are interesting host materials for phosphors, like transparent oxyfluoride glass-ceramics.

In this study, $\mathrm{Eu}_{2} \mathrm{O}_{3}$ was added to the starting materials of the transparent mica glass-ceramics. Eu-doped parent glasses, which were oxyfluoride glasses, were prepared by melting the starting materials in sealed platinum container and were crystallized by heating in air. Then, the influence of Eu-doping on the crystallization of the parent glasses was investigated and the luminescent properties of the parent glasses and the 
obtained glass-ceramics were estimated.

\section{Experimental procedure}

Novel transparent and machinable mica glass-ceramic in which a large quantity of mica was separated was prepared from the parent glass with the chemical compositions corresponding to 94.9 mass $\% \mathrm{Li}_{1.5} \mathrm{Mg}_{3} \mathrm{AlSi}_{4.5} \mathrm{O}_{13.25} \mathrm{~F}_{2}+5.1$ mass\% $\mathrm{MgF}_{2}$ in previous study [3]. The composition of base glass in this study was the same with that of the mica glass-ceramic. $0,0.05,0.5,5,10$ and $20 \mathrm{~mol} \% \mathrm{Eu}_{2} \mathrm{O}_{3}$ were added to the base glass. Such specimens were shown as E0, E005, E05, E5, E10 and E20, respectively, according to the additive amount of $\mathrm{Eu}_{2} \mathrm{O}_{3}$, in this paper. The Eu containing glasses were prepared as follows. The reagents of $\mathrm{MgO}, \mathrm{Al}_{2} \mathrm{O}_{3}, \mathrm{SiO}_{2}, \mathrm{Eu}_{2} \mathrm{O}_{3}, \mathrm{Li}_{2} \mathrm{CO}_{3}$ and $\mathrm{MgF}_{2}$ were mixed, calcined at $900{ }^{\circ} \mathrm{C}$ for $1 \mathrm{~h}$, melted in a sealed platinum container at $1450{ }^{\circ} \mathrm{C}$ for $2 \mathrm{~h}$, and then cooled outside of the furnace. The obtained glasses were annealed in air at about $20{ }^{\circ} \mathrm{C}$ higher temperatures than their glass-transition temperatures and cooled at $2{ }^{\circ} \mathrm{C} / \mathrm{min}$ to eliminate strain. The parent glasses prepared by such a method were cut to dimensions of about $5 \mathrm{~mm} \times 5 \mathrm{~mm} \times 1 \mathrm{~mm}$ and were heated at $600-800{ }^{\circ} \mathrm{C}$ for $1 \mathrm{~h}$ in air to be crystallized. The heating rate was $10^{\circ} \mathrm{C} / \mathrm{min}$.

The thermally change of the parent glasses was analyzed using an X-ray diffraction (XRD) analyzer and a differential thermal analyzer (DTA). The microstructures of the parent glasses and the glass-ceramics were observed using a field emission type scanning electron microscope (FE-SEM) and a transmission electron microscope (TEM). The luminescent properties of the parent glasses and glass-ceramics with thickness of 0.4 $\mathrm{mm}$ were analyzed at room temperature using a fluorescence spectrophotometer. 


\section{Results and discussion}

\subsection{Influence of Eu-doping on crystallization}

The photographs of the parent glasses and the heated glasses are shown in Fig.1. Every parent glass was transparent. While the parent glasses to which 0-5 mol\% $\mathrm{Eu}_{2} \mathrm{O}_{3}$ were added were colorless, those to which $10 \mathrm{~mol} \%$ and $20 \mathrm{~mol}_{\%} \mathrm{Eu}_{2} \mathrm{O}_{3}$ were added were light orange color. Crystals were not detected in every parent glass by XRD analysis. SEM photographs of the polished and etched surfaces of the E05 and E10 parent glasses are shown in Fig.2. In the both glasses, droplet phase, which shows a binodal phase separation, was observed. The size of droplet phase in the E05 parent glass was $50-60 \mathrm{~nm}$ and that in the E10 parent glass was $20-30 \mathrm{~nm}$. In every parent glass, such a binodal phase separation was observed, and the sizes of these droplet phases varied with the additive amount of $\mathrm{Eu}_{2} \mathrm{O}_{3}$.

The phase change in the E5 specimen by heating is shown in Fig. 3. Trace of chondrodite $\left(\mathrm{Mg}_{5}\left(\mathrm{SiO}_{4}\right)_{2} \mathrm{~F}_{2}\right)$ was observed at $600{ }^{\circ} \mathrm{C}$ and a larger amount of chondrodite appeared at $650{ }^{\circ} \mathrm{C}$. Next, mica was separated at $700{ }^{\circ} \mathrm{C}$. The chondrodite acted as nuclei for mica. $\beta$-eucryptite was observed at $750{ }^{\circ} \mathrm{C}$. (This $\beta$-eucryptite was $\beta$-eucryptite solid solution [2].) A large amount of $\beta$-eucryptite appeared at $800{ }^{\circ} \mathrm{C}$. The diffraction peak at about $31^{\circ}$ which was observed at $750{ }^{\circ} \mathrm{C}$ and $800{ }^{\circ} \mathrm{C}$ could not be identified. Probably, it originated in a compound containing Eu. The E5 specimen maintained transparency (Fig. 1(c)) though chondrodite and mica crystals were separated at $600-700{ }^{\circ} \mathrm{C}$. However, it turned white opaque slightly with the separation of $\beta$-eucryptite at $750{ }^{\circ} \mathrm{C}$. Such crystallization process was similar to that of the E0 specimen [3], except for the appearance of the unidentified diffraction peaks.

All specimens, except the E20 specimen, first separated chondrodite at $600{ }^{\circ} \mathrm{C}$ and the amount of the chondrodite increased at $650{ }^{\circ} \mathrm{C}$. The E20 specimen showed only 
trace of chondrodite in the XRD pattern at $650{ }^{\circ} \mathrm{C}$, and already turned white opaque (Fig. 1 (e)). The E10 specimen also turned a little white opaque at $650{ }^{\circ} \mathrm{C}$ (Fig. 1(d)). This white opaque might be caused by the coarsening of the phase separation in the glass phase. XRD patterns of the E0-E20 specimens heated at $700{ }^{\circ} \mathrm{C}$ for $1 \mathrm{~h}$ are shown in Fig. 4. It is obvious that $\mathrm{Eu}_{2} \mathrm{O}_{3}$ addition promoted the separation of mica crystals, compared the XRD patterns of Eu containing specimens with the XRD pattern of the E0 specimen. E005, E05 and E5 specimens separated a larger amount of mica crystals at $700{ }^{\circ} \mathrm{C}$ and maintained the transparency (Fig. 1). The E005 and E05 specimens did not separate $\beta$-eucryptite and unidentified crystal phases (particularly, the crystal phase of which diffraction peak appeared at around $31^{\circ}$ ) at $700{ }^{\circ} \mathrm{C}$. The E5 specimen showed only trace of their crystals in the XRD pattern and their diffraction peak intensities became stronger with an increase in Eu content. Consequently, the E10 and E20 specimens turned more white opaque at $700{ }^{\circ} \mathrm{C}($ Fig. 1 (d) and (e)).

Above results show that a small addition of $\mathrm{Eu}_{2} \mathrm{O}_{3}$ was very effective in preparing transparent glass-ceramics in which a large amount of mica crystals was separated. The $\mathrm{Eu}_{2} \mathrm{O}_{3}$ addition might vary the composition of the droplet and matrix phases in the parent glasses and probably resulted in F- richer droplet phase and $\mathrm{MgO}$ - richer matrix phase, which caused the promotion of separation of mica [3]. However, the excess addition of $\mathrm{Eu}_{2} \mathrm{O}_{3}$, such as $\mathrm{E} 10$ and $\mathrm{E} 20$ specimens, led to the coarsening of phase separation in the glass phase and the separation of a larger amount of the unidentified crystal phases and $\beta$-eucryptite during heating of the parent glasses, which caused white opaque at lower heating temperatures.

TEM images and EDX spectra of the E5 specimen heated at $700{ }^{\circ} \mathrm{C}$ are shown in Fig. 5. Many mica crystals with size of $<150 \mathrm{~nm}$ were separated. A lot of dark parts were observed in the TEM images. Then, the EDX spectra were measured on the dark 
site (M) and the light site (G) which were the mica crystal and the glass phase, respectively. Eu peaks appeared together with $\mathrm{Mg}, \mathrm{Al}, \mathrm{Si}, \mathrm{O}$ and $\mathrm{F}$ peaks in the EDX spectrum of $\mathrm{M}$. ( $\mathrm{Cu}$ and $\mathrm{C}$ peaks originated in the sample holder and the contamination, respectively.) However, no Eu peaks were observed in the EDX spectrum of G though $\mathrm{Mg}, \mathrm{Al}, \mathrm{Si}, \mathrm{O}$ and $\mathrm{F}$ peaks appeared. That is, the dark parts, which were the mica crystals, contained Eu element and the light parts, which were glass phase, did not contain the Eu element. Moreover, the dark straight lines were observed in some mica crystals, which means that all layers of mica crystals did not always contain Eu element uniformly and there were some layers concentrated Eu element in a mica crystal.

The basal spacing (c. $\sin \beta ; c$ and $\beta$ are lattice constants) and lattice constant $b$ of the mica separated in the E0-E5 specimens heated at $700{ }^{\circ} \mathrm{C}$ were determined from the (003) and (060) diffraction peaks, respectively. The obtained basal spacing and lattice constant $\mathrm{b}$ are shown in Fig. 6. In general, the basal spacing, which is the distance between basal planes in the vertical direction relative to the layer, depends mainly on the size of the interlayer cation and the electrostatic repulsion between layers. Furthermore, the lattice constant $\mathrm{b}$ is a standard for determining whether the mica is the tetrasilicic or trisilicic type and the b of tetrasilicic type mica is smaller than that of trisilicic type mica. The composition of mica separated in the E0 specimen was $\mathrm{Li}\left(\mathrm{Mg}_{2+\mathrm{y}} \mathrm{Li}_{1-\mathrm{y}}\right)\left(\mathrm{Al}_{\mathrm{y}} \mathrm{Si}_{4-\mathrm{y}}\right) \mathrm{O}_{10} \mathrm{~F}_{2}(0<\mathrm{y}<1)$ [3]. The interlayer cations were $\mathrm{Li}^{+}$ions, the octahedral sheets contained $\mathrm{Li}^{+}$and $\mathrm{Mg}^{2+}$ ions and the tetrahedral sheets contained $\mathrm{Al}^{3+}$ and $\mathrm{Si}^{4+}$ ions. However, $\mathrm{Li}^{+}$ions are too small to be placed in the interlayer of twelve-coordination. Therefore, if parts of $\mathrm{Li}$ ions in the interlayer are substituted by Eu element $\left(\mathrm{Eu}^{2+}\right.$ and/or $\mathrm{Eu}^{3+}$ ions) which have larger size than the other cations in the specimen, the structure of the micas will become more stable. Actually, it is clear from Fig. 5 that the mica crystals contained $\mathrm{Eu}$ element. The $\mathrm{Eu}$ element $\left(\mathrm{Eu}^{2+}\right.$ and/or $\mathrm{Eu}^{3+}$ 
ions) must be substituted for $\mathrm{Li}^{+}$ions in the interlayer of mica to stabilize mica structure. However, the basal spacing and lattice constant $\mathrm{b}$ of the mica separated in the Eu containing specimens were almost the same with those of the mica separated in the E0 specimen. The basal spacing should be increased by substituting larger cations for $\mathrm{Li}^{+}$ ions in the interlayer. On the other hand, the number of interlayer cations was decreased by substituting divalent and/or trivalent cations for $\mathrm{Li}^{+}$ions in the interlayer, which should caused the decrease in the basal spacing. Consequently, substituting $\mathrm{Eu}^{2+}$ and/or $\mathrm{Eu}^{3+}$ ions for $\mathrm{Li}^{+}$ions in the interlayer did not vary not only the lattice constant $\mathrm{b}$ but also the basal spacing.

\subsection{Luminescent properties}

Emission spectra of the E5 specimen excited at $254 \mathrm{~nm}$ are shown in Fig. 7. The peaks at around $590 \mathrm{~nm}$ and $610 \mathrm{~nm}$ were observed for the E5 parent glass, which originated in ${ }^{5} \mathrm{D}_{0} \rightarrow{ }^{7} \mathrm{~F}_{\mathrm{J}}$ transition of $\mathrm{Eu}^{3+}$ ions. In addition, the weak, broad and discontinuous peak at around $400 \mathrm{~nm}$ was also observed, which originated in $4 \mathrm{f}^{6} 5 \mathrm{~d} \rightarrow$ $4 \mathrm{f}^{7}$ transition of $\mathrm{Eu}^{2+}$ ion. These results mean that parts of $\mathrm{Eu}^{3+}$ ions which were added as $\mathrm{Eu}_{2} \mathrm{O}_{3}$ were reduced to $\mathrm{Eu}^{2+}$ ions during melting of the starting materials. While the peaks at around $590 \mathrm{~nm}$ and $610 \mathrm{~nm}$ became weaker with an increase in heating temperature, the broad peak at around $400 \mathrm{~nm}$ became stronger, especially, the peak was stronger than the peaks at around $590 \mathrm{~nm}$ and $610 \mathrm{~nm}$ at $700{ }^{\circ} \mathrm{C}$. However, all peaks became much weaker at $750{ }^{\circ} \mathrm{C}$ because the E5 specimen turned white opaque. In this way, $\mathrm{Eu}^{3+}$ ions were reduced to $\mathrm{Eu}^{2+}$ ions during heating in air and an amount of $\mathrm{Eu}^{2+}$ ions was increased with an increase in heating temperature. So the E5 parent glass emitted red light by the excitation at $254 \mathrm{~nm}$, and the E5 specimens heated at $700{ }^{\circ} \mathrm{C}$ and $750{ }^{\circ} \mathrm{C}$ emitted violet light. Similar luminescence properties were observed for 
other Eu containing specimens in this study.

The reduction of $\mathrm{Eu}^{3+}$ to $\mathrm{Eu}^{2+}$ ions in air has been reported for some inorganic phosphors [11-21]. It has been observed for $\mathrm{SrF}_{3}$ nanocrystals and Eu containing

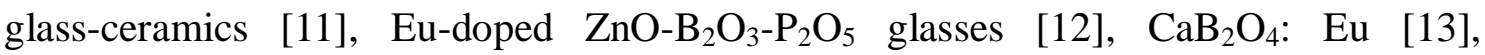
$\mathrm{M}_{2} \mathrm{~B}_{5} \mathrm{O}_{9} \mathrm{Cl}: \mathrm{Eu}(\mathrm{M}=\mathrm{Ca}, \mathrm{Sr}, \mathrm{Ba})$ [14], $\mathrm{Sr}_{4} \mathrm{Al}_{14} \mathrm{O}_{25}: \mathrm{Eu}$ [15], $\mathrm{BaMgSiO}_{4}: \mathrm{Eu}$ [16], $\mathrm{LnBPO}_{5}$ : $\mathrm{Eu}(\mathrm{Ln}=\mathrm{Ca}, \mathrm{Sr})$ [17], $\mathrm{SrB}_{5} \mathrm{O}_{9} \mathrm{Cl}: \mathrm{Eu}$ [18], and $\mathrm{SrB}_{4} \mathrm{O}_{7}: \mathrm{Eu}$ [19]. Their reduction mechanism is explained as follows [11-19]. When three $\mathrm{M}^{2+}$ ions such as $\mathrm{Ca}^{2+}, \mathrm{Sr}^{2+}$, $\mathrm{Ba}^{2+}$ and $\mathrm{Zn}^{2+}$ ions are replaced by only two $\mathrm{Eu}^{3+}$ ions, a negative vacancy ( $\mathrm{V}_{\mathrm{M}}$ ") is formed $\left(3 \mathrm{M}_{\mathrm{M}}{ }^{\times}+2 \mathrm{Eu}^{3+} \rightarrow 3 \mathrm{M}^{2+}+\mathrm{V}_{\mathrm{M}}{ }^{\prime \prime}+2 \mathrm{Eu}_{\mathrm{M}}{ }^{\circ}\right)$. The negative charges in the vacancy $\left(\mathrm{V}_{\mathrm{M}}{ }^{\prime \prime}\right)$ are transferred to the $\mathrm{Eu}^{3+}$ ions sites $\left(2 \mathrm{Eu}_{\mathrm{M}}{ }^{\circ}\right)$ and reduce $\mathrm{Eu}^{3+}$ to $\mathrm{Eu}^{2+}$ ions $\left(\mathrm{V}_{\mathrm{M}}{ }^{\prime \prime}\right.$ $\left.\rightarrow \mathrm{V}_{\mathrm{M}}{ }^{\times}+2 \mathrm{e}, 2 \mathrm{Eu}_{\mathrm{M}}{ }^{\cdot}+2 \mathrm{e} \rightarrow 2 \mathrm{Eu}_{\mathrm{M}}{ }^{\times}\right)$. On the other hand, the reduction is observed when the glasses with the compositions of $\mathrm{BaB}_{8} \mathrm{O}_{13}: \mathrm{Eu}$ [20] and $\mathrm{MB}_{4} \mathrm{O}_{7}: \mathrm{Eu}(\mathrm{M}=\mathrm{Sr}, \mathrm{Ba})$ [21] are crystallized. The reduction mechanism is explained as follows $[20,21]$. When the non-bridging oxygens of $\mathrm{BO}_{3}$ units in such glasses are connected one another to form $\mathrm{BO}_{4}$ units in crystallization process of the glasses, $\mathrm{Eu}^{3+}$ ions are reduced by evolving the resulting free oxygens and the converted $\mathrm{Eu}^{2+}$ ions are stabilized by occupaying the $\mathrm{Sr}^{2+}$ or $\mathrm{Ba}^{2+}$ ions sites. Our specimens contained $\mathrm{Mg}^{2+}$ ions as the divalent cations but the size of $\mathrm{Mg}^{2+}$ ion was too small to be replaced by $\mathrm{Eu}^{3+}$ ions, moreover, our parent glasses did not contain $\mathrm{BO}_{3}$ units. Therefore, the reduction mechanism of $\mathrm{Eu}^{3+}$ to $\mathrm{Eu}^{2+}$ ions in this study should be different from above two explanations. A feature of the glasses prepared in this study is that fluorine and/or fluorides evaporated during heating. We reported that fluorine and fluorides such as $\mathrm{AlF}_{3}$ evaporated from the glass with composition of $\mathrm{KMg}_{3} \mathrm{AlSi}_{3} \mathrm{O}_{10} \mathrm{~F}_{2}$ (fluorophlogopite) at $>800{ }^{\circ} \mathrm{C}$ [22]. That is, the reduction of $\mathrm{Eu}^{3+}$ to $\mathrm{Eu}^{2+}$ ions in this study might be caused by evolving fluorine from the melt and glass phase. When the starting materials were melted in the sealed 
platinum container, fluorine might evaporate from the melt, which resulted in the reduction of $\mathrm{Eu}^{3+}$ ions. Furthermore, when the parent glasses were heated in air to be crystallized, particularly, at $\geqq 700{ }^{\circ} \mathrm{C}$, a larger amount of fluorine might evaporate from the glass phases and a larger amount of $\mathrm{Eu}^{3+}$ ions were reduced. Since the specimens in this study contained a larger amount of fluorine than the glass with composition of $\mathrm{KMg}_{3} \mathrm{AlSi}_{3} \mathrm{O}_{10} \mathrm{~F}_{2}$ (fluorophlogopite) [22], fluorine might evaporate at $<800{ }^{\circ} \mathrm{C}$.

The excitation spectrum (emission spectrum: $405 \mathrm{~nm}$ ) and emission spectrum (excitation spectrum: $289 \mathrm{~nm}$ ) of the E5 parent glass are shown in Fig. 8. The excitation peak was observed at $289 \mathrm{~nm}$, which ascribed to the $4 \mathrm{f}-5 \mathrm{~d}$ transition of $\mathrm{Eu}^{2+}$ ions [12]. When the parent glass was excited at $289 \mathrm{~nm}$, the broad emission peak which was similar to that shown in Fig. 7(d) appeared at around $400 \mathrm{~nm}$. And it was discontinuous peak, especially at $394 \mathrm{~nm}$. The excitation spectrum (emission spectrum: $610 \mathrm{~nm}$ ) and emission spectrum (excitation spectrum: $394 \mathrm{~nm}$ ) of the E5 parent glass are shown in Fig. 9. The some sharp excitation peaks were observed at 350-550 nm, which ascribed to the transitions between the $4 \mathrm{f}$ energy levels of $\mathrm{Eu}^{3+}$ ions $[11,12]$, particularly, the excitation peak at $394 \mathrm{~nm}$ was the strongest. When the parent glass was excited at 394 $\mathrm{nm}$, the emission peak appeared at around 590 and $610 \mathrm{~nm}$, which originated in $\mathrm{Eu}^{3+}$ ions. These results indicate that $\mathrm{Eu}^{3+}$ ions absorbed the parts of the emission of $\mathrm{Eu}^{2+}$ ions, particularly the light of $394 \mathrm{~nm}$, were excited by the light adsorbed from the emission of $\mathrm{Eu}^{2+}$ ions and then emitted the light of around $590 \mathrm{~nm}$ and $610 \mathrm{~nm}$. Consequently, the emission peak at around $400 \mathrm{~nm}$ of $\mathrm{Eu}^{2+}$ ions results in the discontinuous, particularly at $394 \mathrm{~nm}$, and is seemed to be the broad emission containing several peaks, as shown in Fig. 7 and Fig. 8, though it is one continuous broad emission peak originally by the $4 \mathrm{f}^{6} 5 \mathrm{~d} \rightarrow 4 \mathrm{f}^{7}$ transition of $\mathrm{Eu}^{2+}$ ion. That is, these results mean that the energy transfer from $\mathrm{Eu}^{2+}$ ions to $\mathrm{Eu}^{3+}$ ions occurred. The energy 
corresponding to the $4 \mathrm{f}^{6} 5 \mathrm{~d} \rightarrow{ }^{8} \mathrm{~S}_{7 / 2}$ transition of $\mathrm{Eu}^{2+}$ ions caused to excite $\mathrm{Eu}^{3+}$ ions [23, 24], particularly, ${ }^{7} \mathrm{~F}_{0} \rightarrow{ }^{5} \mathrm{~L}_{6}$ transition which is corresponding to energy level of $394 \mathrm{~nm}$. Changes in emission intensities at $405 \mathrm{~nm}$ and $610 \mathrm{~nm}$ of the parent glasses and the specimens heated at $700{ }^{\circ} \mathrm{C}$ with an increase in $\mathrm{Eu}_{2} \mathrm{O}_{3}$ content are shown in Fig. 10. The emission intensities at $405 \mathrm{~nm}$ and $610 \mathrm{~nm}$ of the parent glasses were decreased by addition of $20 \mathrm{wt} \% \mathrm{Eu}_{2} \mathrm{O}_{3}$. That is, the concentration quenching did not occur even for the parent glass having such high $\mathrm{Eu}_{2} \mathrm{O}_{3}$ concentration as $10 \mathrm{~mol} \%$. On the other hand, the emission intensities of the heated specimens were decreased by addition of 10 mol\% $\mathrm{Eu}_{2} \mathrm{O}_{3}$, which might not result from concentration quenching. As the additive amount of $\mathrm{Eu}_{2} \mathrm{O}_{3}$ increased, white opaque of the specimens occurred at lower heating temperatures. That is, such decreases in the intensities resulted from the white opaque.

\section{Conclusions}

We fabricated the novel phosphors which were transparent and machinable mica glass-ceramics containing $\mathrm{Eu}^{2+}$ and $\mathrm{Eu}^{3+}$ ions. And the influence of $\mathrm{Eu}_{2} \mathrm{O}_{3}$ addition on the crystallization of the parent glasses was investigated and the luminescent properties of the parent glasses and the glass-ceramics were estimated.

A small additive amount of $\mathrm{Eu}_{2} \mathrm{O}_{3}$ was very effective in preparing transparent mica glass-ceramics. However, the excess addition led to the coarsening of phase separation in the glass phase and the separation of a larger amount of unidentified crystal phases and $\beta$-eucryptite during heating of the parent glasses, which caused white opaque at lower heating temperatures. When the mica crystals were separated, Eu ions $\left(\mathrm{Eu}^{2+}\right.$ and/or $\mathrm{Eu}^{3+}$ ) were substituted for $\mathrm{Li}^{+}$ions in the interlayer of mica crystals. However, all layers of mica crystals did not always contain the $\mathrm{Eu}$ ions uniformly and there were some layers which concentrated the Eu ions in a mica crystal. 
When the parent glasses excited at $254 \mathrm{~nm}$, emission peaks appeared at around 590 $\mathrm{nm}$ and $610 \mathrm{~nm}$, which originated in $\mathrm{Eu}^{3+}$ ions and the weak, broad and discontinuous emission peak appeared at around $400 \mathrm{~nm}$, which originated in $\mathrm{Eu}^{2+}$ ion. While the former peaks became weaker by heating in air, the latter peak became stronger.

It was obvious from the emission spectra that parts of $\mathrm{Eu}^{3+}$ ions were reduced to $\mathrm{Eu}^{2+}$ ions during melting of the starting materials and during heating in air to be crystallized. This reduction of $\mathrm{Eu}^{3+}$ to $\mathrm{Eu}^{2+}$ ions might be caused by evolving fluorine from the specimens during the melting and the heating. The $\mathrm{Eu}^{3+}$ ions were excited by emission of $\mathrm{Eu}^{2+}$ ions, particularly, emission at $394 \mathrm{~nm}$, and emitted the light of around $590 \mathrm{~nm}$ and $610 \mathrm{~nm}$. That is, the energy transfer from $\mathrm{Eu}^{2+}$ ions to $\mathrm{Eu}^{3+}$ ions occurred.

The concentration quenching did not occur even for the parent glass having such high $\mathrm{Eu}_{2} \mathrm{O}_{3}$ concentration as $10 \mathrm{~mol} \%$. On the other hand, as the additive amount of $\mathrm{Eu}_{2} \mathrm{O}_{3}$ increased, the white opaque occurred by heating at lower temperatures, which decreased the emission intensities of the glass-ceramics. 


\section{References}

[1] G. H. Beall, L. R. Pinckney, Nanophase glass-ceramics. J. Am. Ceram. Soc., 82 (1999) 5-16.

[2] S. Taruta, T. Ichinose, T. Yamaguchi, K. Kitajima, Preparation of transparent lithium-mica glass-ceramics. J. Non-Cryst. Solids, 352 (2006) 5556-5563.

[3] S. Taruta, M. Suzuki, T. Yamaguchi, K. Kitajima, Preparation and ionic conductivity of transparent glass-ceramics containing a large quantity of lithium-mica. J. Non-Cryst. Solids, 354 (2008) 848-855.

[4] S. Lyng, J. Markali, J. Krogh-Moe, N. H. Lundberg, On the crystallization in aluminosilicate glass containing fluoride and magnesia. Physics Chem. Glasses, 11 (1970) 6-10.

[5] Card No. 16-344, Joint Committee on Powder Diffraction Standards, Swarthmore, PA.

[6] K. Kitajima, S. Taruta, N. Takusagawa, Effect of layer charge on the IR spectra of synthetic fluorine micas. Clay Minerals, 26 (1991) 435-440.

[7] H. Toraya, S. Iwai, F. Marumo, M. Hirao, The crystal structure of taeniolite, $\mathrm{KLiMg}_{2} \mathrm{Si}_{4} \mathrm{O}_{10} \mathrm{~F}_{2}$. Z. Kristallogr., 146 (1977) 73-83.

[8] H. Toraya, S. Iwai, F. Marumo, M. Daimon, R. Kondo, The crystal structure of tetrasilisic potassium fluor mica, $\mathrm{KMg}_{2.5} \mathrm{Si}_{4} \mathrm{O}_{10} \mathrm{~F}_{2}$. Z. Kristallogr., 144 (1976) $42-52$

[9] S. N. Hoda. G. H. Beall, Alkaline earth mica galss-ceramics. In Advances in Nucleation and Crystallization in Glasses, ed. J. H. Simmous, D. R. Uhlmann and G. H. Beall. Am Ceram. Soc., Westerville, OH, 1982, pp. 287-300.

[10] Card No. 29-181, Joint Committee on Powder Diffraction Standards, Swarthmore, PA. 
[11] Q. Luo, X. Qiao, X. Fan, S. Liu, H. Yang, X. Zhang, Reduction and Luminescence of europium ions in glass ceramics containing SrF2 nanocrystals. J. Non-Cryst. Solids, 354 (2008) 4691-4694.

[12] Z. Lian, J. Wang, Y. Lv, S. Wang, Q. Su, The reduction of $\mathrm{Eu}^{3+}$ to $\mathrm{Eu}^{2+}$ in air and luminescence properties of $\mathrm{Eu}^{2+}$ activated $\mathrm{ZnO}-\mathrm{B}_{2} \mathrm{O}_{3}-\mathrm{P}_{2} \mathrm{O}_{5}$ glasses. J. Alloys Compd., 430 (2007) 257-261.

[13] J. H. Hao, J. Gao, Abnormal reduction of $\mathrm{Eu}$ ions and luminescence in $\mathrm{CaB}_{2} \mathrm{O}_{4}$ : $\mathrm{Eu}$ thin films. Appl. Phys. Lett., 85 (2004) 3720-3722.

[14] J. Hao, J. Gao, M. Cocivera, Turing of the blue emission from europium-doped alkaline earth choroborate thin films activated in air. Appl. Phys. Lett., 82 (2004) 2778-2780.

[15] M. Peng, Z. Pei, G. Hong, Q. Su, Study on the reduction of $\mathrm{Eu}^{3+} \rightarrow \mathrm{Eu}^{2+}$ in $\mathrm{Sr}_{4} \mathrm{Al}_{14} \mathrm{O}_{25}$ : Eu prepared in air atmosphere. Chem. Phys. Lett., 371 (2003) 1-6.

[16] M. Peng, Z. Pei, G. Hong, Q. Su, The reduction of $\mathrm{Eu}^{3+}$ to $\mathrm{Eu}^{2+}$ in $\mathrm{BaMgSiO}_{4}$ : $\mathrm{Eu}^{2+}$ phosphor. J. Mater. Chem., 13 (2003) 1202-1205.

[17] Q. Su, H. Liang, T. Hu, Y. Tao, T. Liu, Preparation of divalent rare earth ions in air by aliovalent substitution and spectroscopic properties of $\mathrm{Ln}^{2+}$. J. Alloys Compd., 344 (2002) 132-136.

[18] Z. Pei, Q. Zeng, Q. Su, A study on the mechanism of the abnormal reduction of $\mathrm{Eu}^{3+} \rightarrow \mathrm{Eu}^{2+}$ in $\mathrm{Sr}_{2} \mathrm{~B}_{5} \mathrm{O}_{9} \mathrm{Cl}$ prepared in air at high temperature. J. Solid State Chem., 145 (1999) 212-215.

[19] Z. Pei, Q. Su, J. Zhang, The valence change from $\mathrm{RE}^{3+}$ to $\mathrm{RE}^{2+}(\mathrm{RE} \equiv \mathrm{Eu}, \mathrm{Sm}, \mathrm{Yb})$ in $\mathrm{SrB}_{4} \mathrm{O}_{7}$ : RE prepared in air and spectral properties of $\mathrm{RE}^{2+}$. J. Alloys Compd., 198 (1993) 51-53.

[20] K. Machida, D. Ueda, S. Inoue, G. Adachi, Structural modification-induced valence 
change of the europium ion doped in barium octaborate. Electrochem. Solid-State Lett., 2 (1999) 597-599.

[21] K. Machida, D. Ueda, S. Inoue, G. Adachi, Reversible valence change of the europium ion doped in alkaline-earth tetraborates. Chem. Lett., 18 (1999) 785-786.

[22] S. Taruta, T. Hayashi, K. Kitajima, Preparation of machinable cordierite/mica composite by low temperature sintering. J. Eur. Ceram. Soc., 24 (2004) 3149-3154.

[23] H. Xia, J. Zhang, J. Wang. Q. Nie, H. Song, Preparation and optical spectroscopy of $\mathrm{Li}_{2} \mathrm{O}-\mathrm{Al}_{2} \mathrm{O}_{3}-\mathrm{SiO}_{2}$ glasses containing divalent and trivalent europium ions. Matter. Lett., 53 (2002) 277-281.

[24] M. Nogami, T. Yamazaki, Y. Abe, Fluorescence properties of $\mathrm{Eu}^{3+}$ and $\mathrm{Eu}^{2+}$ in $\mathrm{Al}_{2} \mathrm{O}_{3}-\mathrm{SiO}_{2}$ glass. J. Lumin., 78 (1998) 63-68. 


\section{Figure legends}

Fig. 1. Photographs of parent glasses and the glasses heated at $600{ }^{\circ} \mathrm{C}, 650{ }^{\circ} \mathrm{C}, 700{ }^{\circ} \mathrm{C}$ and $750{ }^{\circ} \mathrm{C}$ for $1 \mathrm{~h}$. (a) E005, (b) E05, (c) E5, (d) E10 and (e) E20 specimens.

Fig. 2. SEM images of polished and chemically etched surfaces of (a) E05 and (b) E10 parent glasses.

Fig. 3. XRD patterns of (a) E5 parent glass and E5 specimen heated at (b) $600{ }^{\circ} \mathrm{C}$, (c) $650{ }^{\circ} \mathrm{C}$, (d) $700{ }^{\circ} \mathrm{C}$, (e) $750{ }^{\circ} \mathrm{C}$ and (f) $800{ }^{\circ} \mathrm{C}$ for $1 \mathrm{~h}$.

Fig. 4. XRD patterns of (a) E0, (b) E005, (c) E05, (d) E5, (e) E10 and (f) E20 specimens heated at $700{ }^{\circ} \mathrm{C}$ for $1 \mathrm{~h}$.

Fig. 5. TEM images of E5 specimen heated at $700{ }^{\circ} \mathrm{C}$ for $1 \mathrm{~h}$; (a) low magnification and (b) high magnification. EDX spectra of (c) dark site (M) and (d) light site (G) in the Fig. 5(a).

Fig. 6. Relationship between basal spacing $(c \cdot \sin \beta)$ and lattice constant (b) of mica crystals separated in $(\bullet)$ E0, (•) E005, (^) E05 and $(\bullet)$ E5 specimens heated at $700{ }^{\circ} \mathrm{C}$ for $1 \mathrm{~h}$.

Trisilicic type mica: $\left(\nabla^{4}, \odot^{5}\right) \mathrm{K}$-phlogopite $\left(\mathrm{KMg}_{3}\left(\mathrm{AlSi}_{3} \mathrm{O}_{10}\right) \mathrm{F}_{2}\right)$ and $\left(\triangleright^{9}\right)$ Ca-phlogopite $\left(\mathrm{Ca}_{0.5} \mathrm{Mg}_{3}\left(\mathrm{AlSi}_{3} \mathrm{O}_{10}\right) \mathrm{F}_{2}\right)$.

Tetrasilicic type mica: $\left(\circ^{6}, \triangleleft^{7}\right)$ K-taeniolite $\left(\mathrm{KMg}_{2} \mathrm{Li}_{(}\left(\mathrm{Si}_{4} \mathrm{O}_{10}\right) \mathrm{F}_{2}\right),\left(\diamond^{6}\right)$ Na-taeniolite $\left(\mathrm{NaMg}_{2} \mathrm{Li}\left(\mathrm{Si}_{4} \mathrm{O}_{10}\right) \mathrm{F}_{2}\right)$, and $\left(\odot^{8}\right) \mathrm{K}$-tetrasilisic mica $\left(\mathrm{KMg}_{2.5}\left(\mathrm{Si}_{4} \mathrm{O}_{10}\right) \mathrm{F}_{2}\right)$.

Brittle mica: $\left(\Delta^{10}\right)$ Kinoshitalite $\left(\mathrm{BaMg}_{3}\left(\mathrm{Al}_{2} \mathrm{Si}_{2} \mathrm{O}_{10}\right)(\mathrm{OH})_{2}\right)$. 
Fig. 7. Emission spectra of (a) E5 parent glass and E5 specimen heated at (b) $600{ }^{\circ} \mathrm{C}$, (c) $650{ }^{\circ} \mathrm{C}$, (d) $700{ }^{\circ} \mathrm{C}$ and (e) $750{ }^{\circ} \mathrm{C}$ for $1 \mathrm{~h}$; excitation spectrum, $\lambda_{\mathrm{ex}}=254 \mathrm{~nm}$.

Fig. 8. Excitation (solid line) and emission spectra (dashed line) of E5 parent glass; emission spectrum, $\lambda_{\mathrm{em}}=405 \mathrm{~nm}$; excitation spectrum, $\lambda_{\mathrm{ex}}=289 \mathrm{~nm}$.

Fig. 9. (a) Excitation and (b) emission spectra of E5 parent glass; emission spectrum, $\lambda_{\mathrm{em}}=610 \mathrm{~nm}$; excitation spectrum, $\lambda_{\mathrm{ex}}=349 \mathrm{~nm}$.

Fig. 10. Changes in emission intensities at (a) $405 \mathrm{~nm}$ and (b) $610 \mathrm{~nm}$ of (o) parent glasses and $(\bullet)$ specimens heated at $700{ }^{\circ} \mathrm{C}$ for $1 \mathrm{~h}$ with an increase in $\mathrm{Eu}_{2} \mathrm{O}_{3}$ content; excitation spectrum, $\lambda_{\mathrm{ex}}=254 \mathrm{~nm}$. 


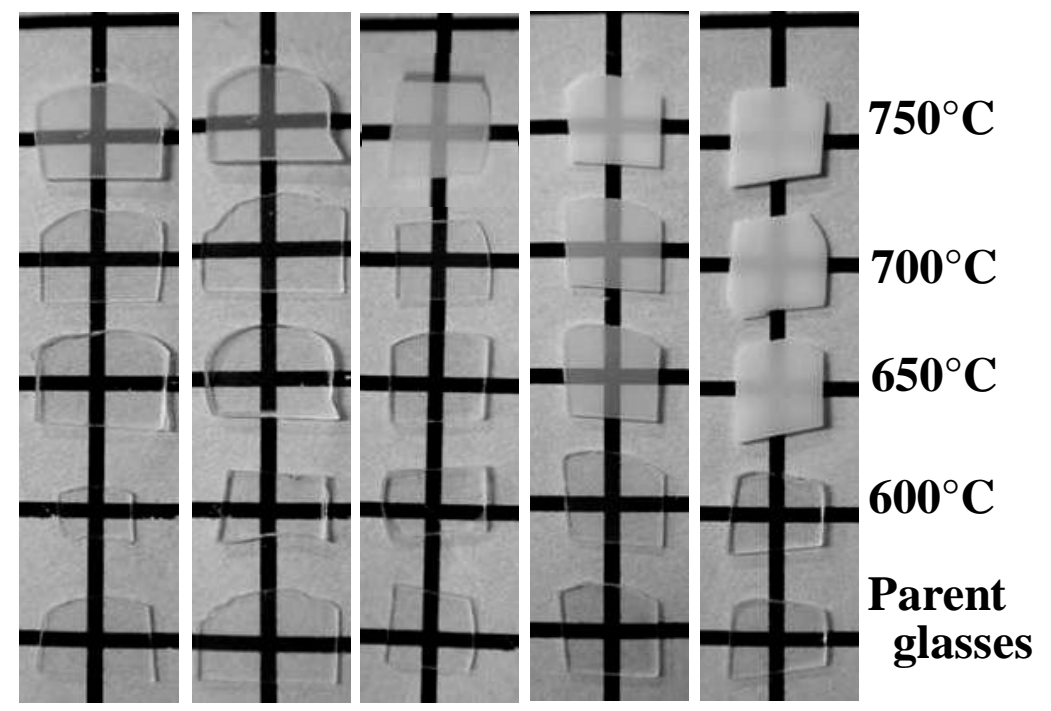
(a)
(b)
(c)
(d)
(e)

Fig. 1. Photographs of parent glasses and the glasses heated at $600{ }^{\circ} \mathrm{C}, 650^{\circ} \mathrm{C}$, $700{ }^{\circ} \mathrm{C}$ and $750{ }^{\circ} \mathrm{C}$ for $1 \mathrm{~h}$. (a) E005, (b) E05, (c) E5, (d) E10 and (e) E20 specimens. 


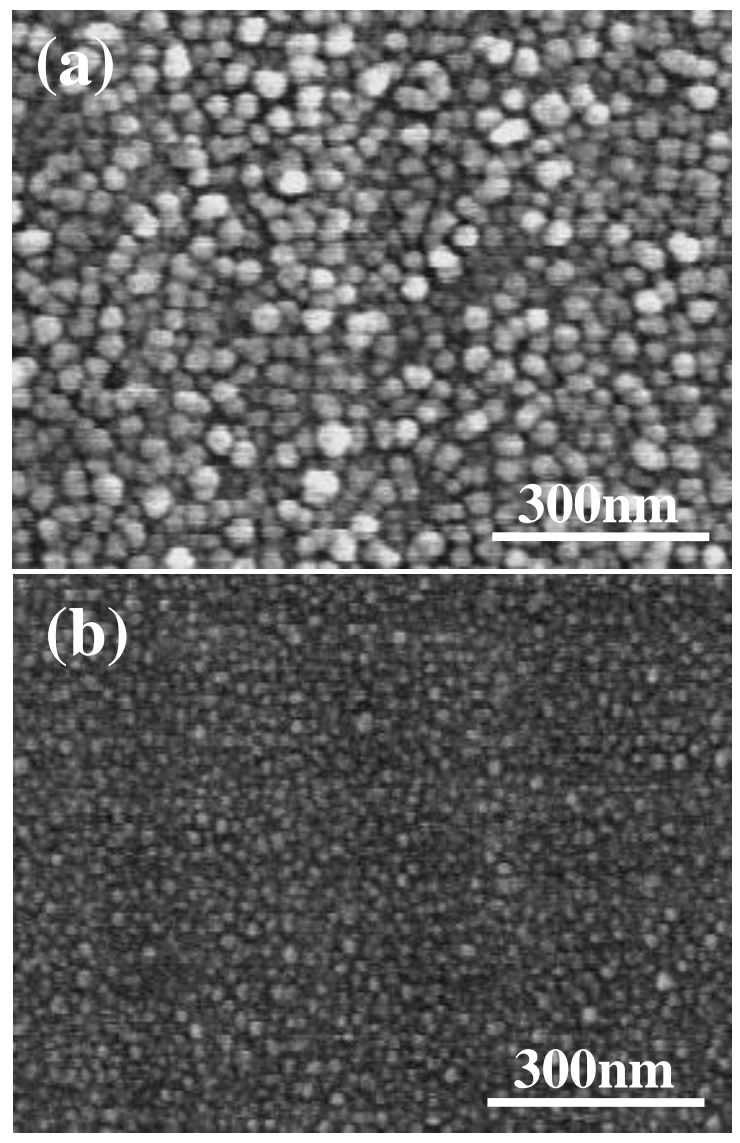

Fig. 2. SEM images of polished and chemically etched surfaces of (a) E05 and (b) E10 parent glasses. 


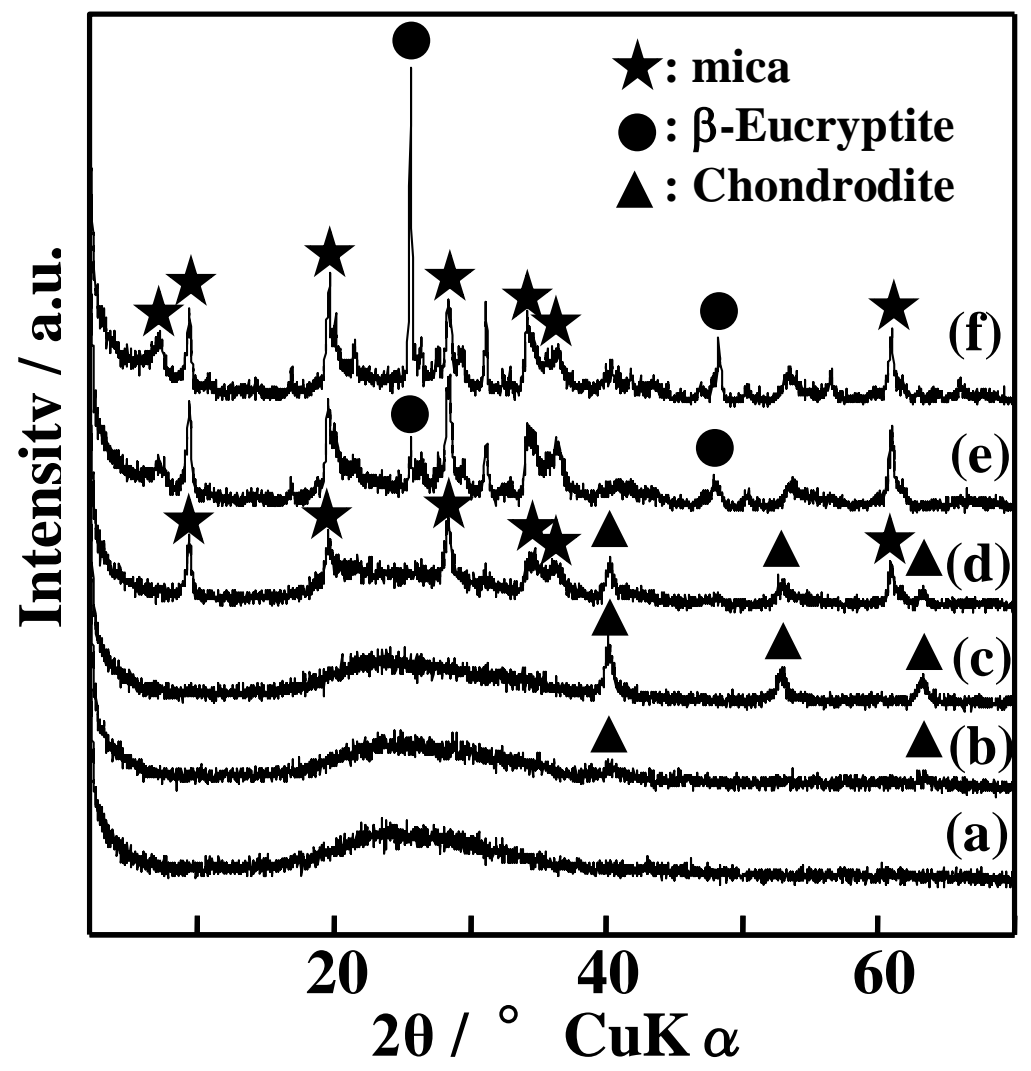

Fig. 3. XRD patterns of (a) E5 parent glass and E5 specimen heated at (b) $600{ }^{\circ} \mathrm{C}$, (c) $650{ }^{\circ} \mathrm{C}$, (d) $700{ }^{\circ} \mathrm{C}$, (e) $750{ }^{\circ} \mathrm{C}$ and (f) $800{ }^{\circ} \mathrm{C}$ for $1 \mathrm{~h}$. 


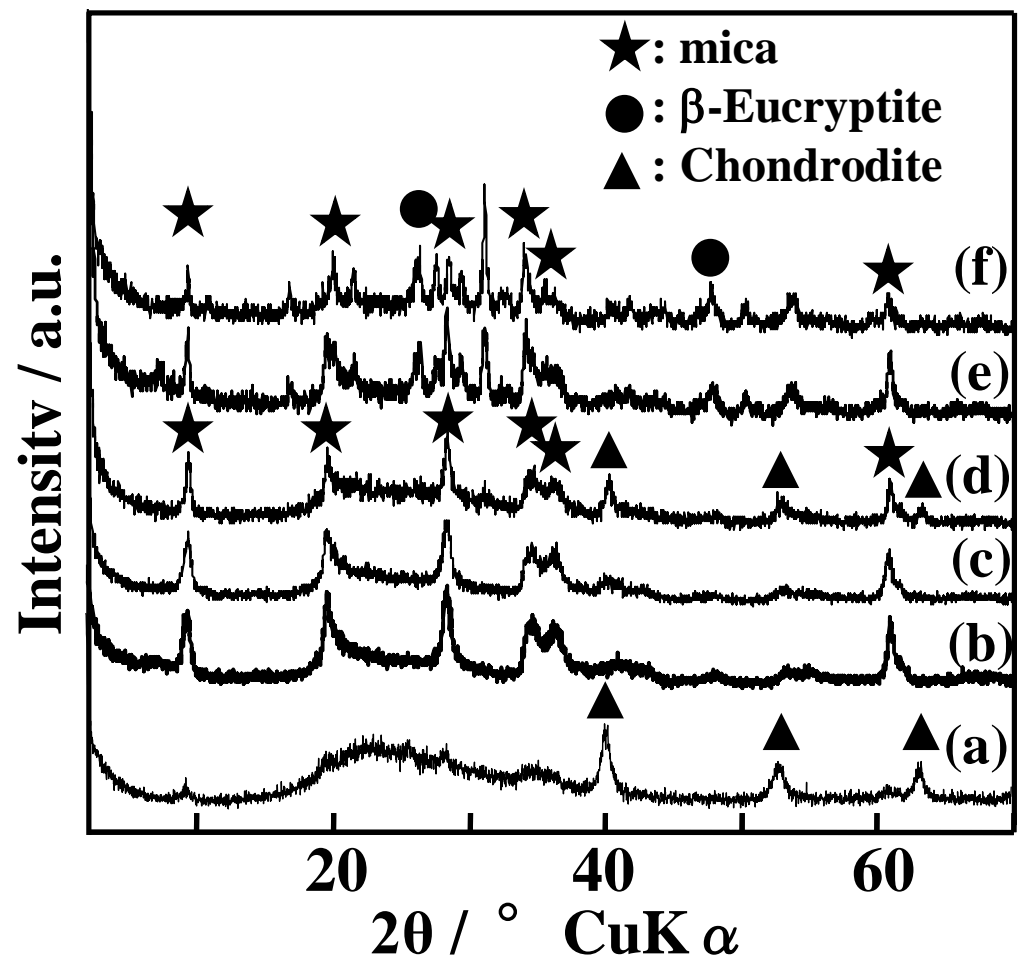

Fig. 4. XRD patterns of (a) E0, (b) E005, (c) E05, (d) E5, (e) E10 and (f) E20 specimens heated at $700{ }^{\circ} \mathrm{C}$ for $1 \mathrm{~h}$. 

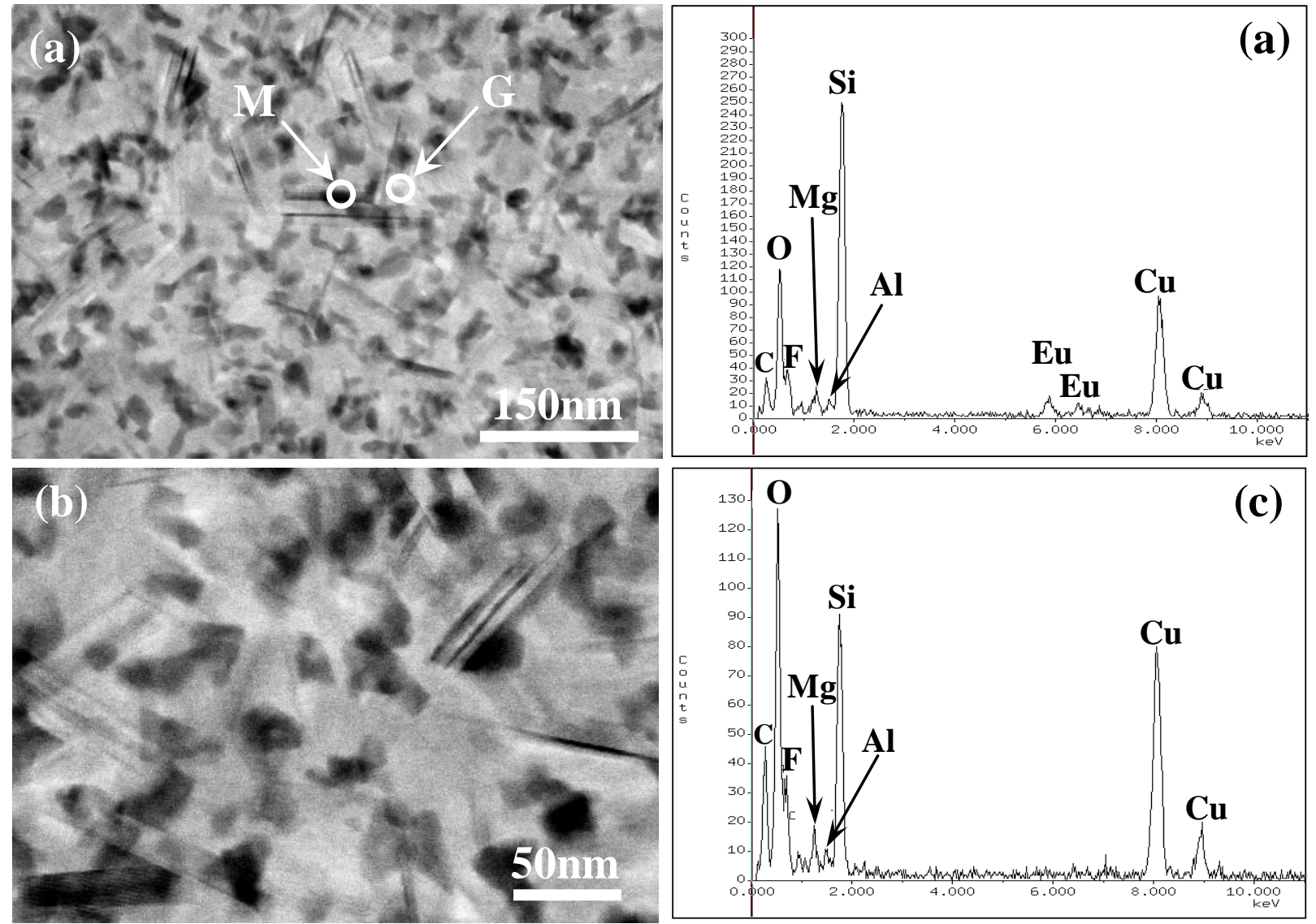

Fig. 5. TEM images of E5 specimen heated at $700{ }^{\circ} \mathrm{C}$ for $1 \mathrm{~h}$; (a) low magnification and (b) high magnification. EDX spectra of (c) dark site (M) and (d) light site (G) in the Fig. 5(a). 


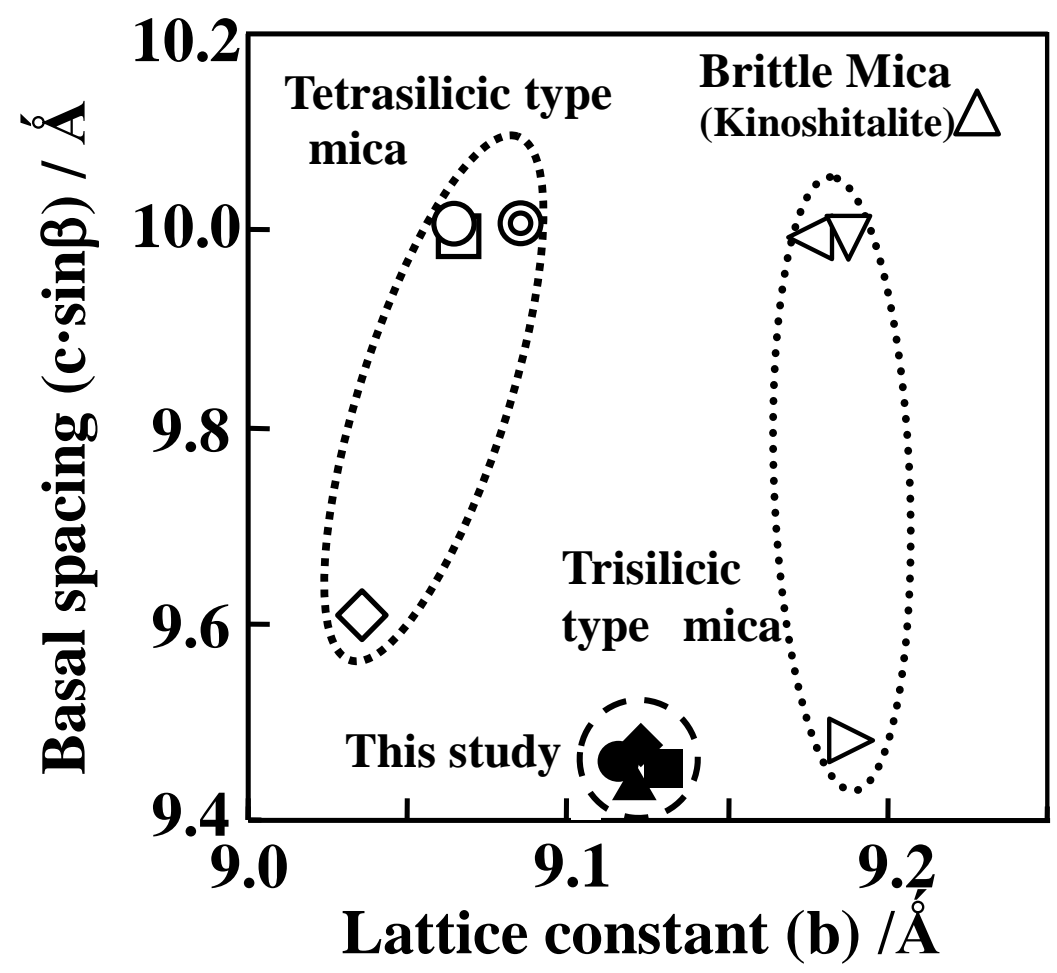

Fig. 6. Relationship between basal spacing $(c \cdot \sin \beta)$ and lattice constant (b) of mica

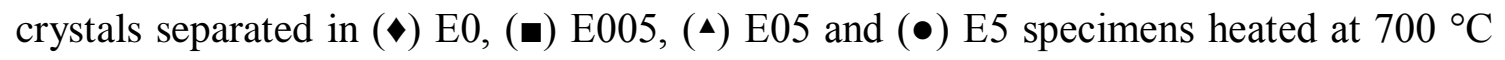
for $1 \mathrm{~h}$.

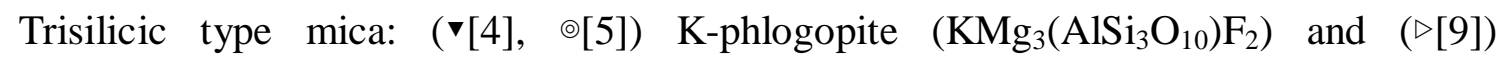
Ca-phlogopite $\left(\mathrm{Ca}_{0.5} \mathrm{Mg}_{3}\left(\mathrm{AlSi}_{3} \mathrm{O}_{10}\right) \mathrm{F}_{2}\right)$.

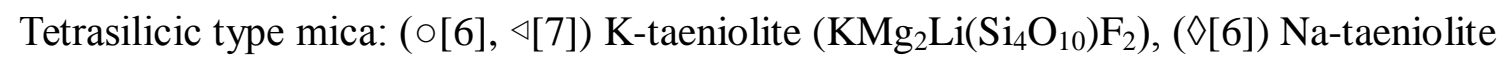
$\left(\mathrm{NaMg}_{2} \mathrm{Li}\left(\mathrm{Si}_{4} \mathrm{O}_{10}\right) \mathrm{F}_{2}\right)$, and (॰[8]) K-tetrasilisic mica $\left(\mathrm{KMg}_{2.5}\left(\mathrm{Si}_{4} \mathrm{O}_{10}\right) \mathrm{F}_{2}\right)$.

Brittle mica: $(\Delta[10])$ Kinoshitalite $\left(\mathrm{BaMg}_{3}\left(\mathrm{Al}_{2} \mathrm{Si}_{2} \mathrm{O}_{10}\right)(\mathrm{OH})_{2}\right)$. 


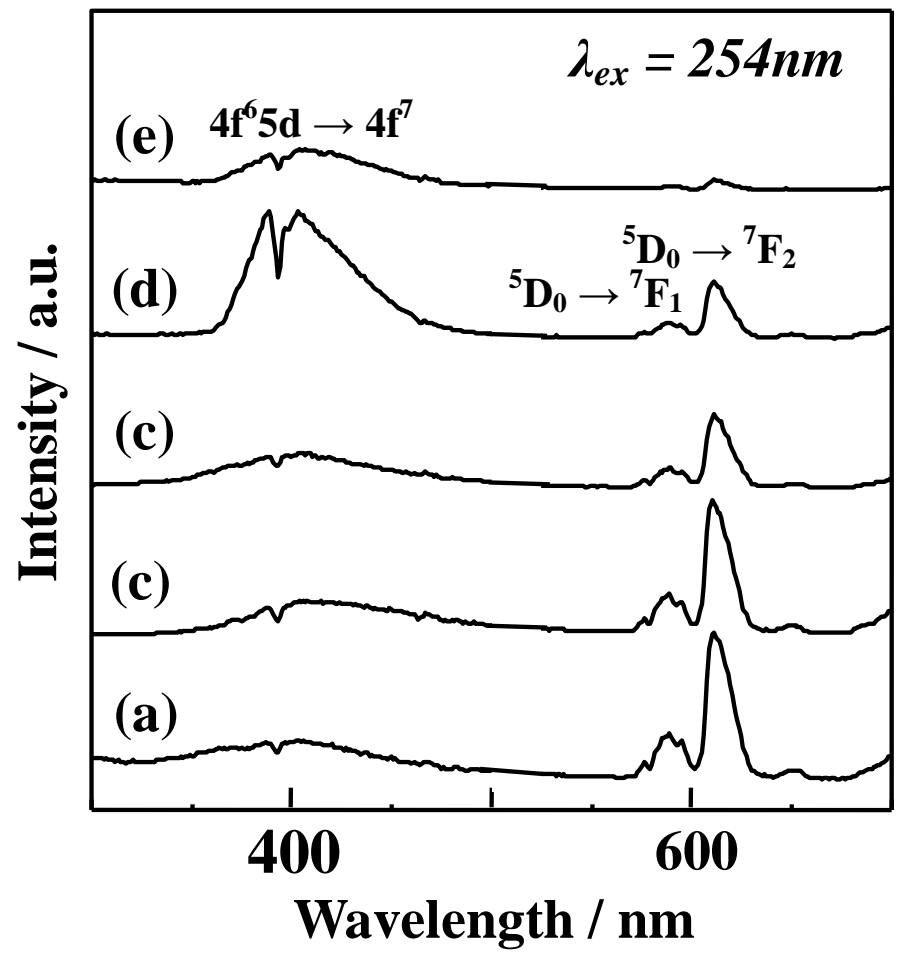

Fig. 7. Emission spectra of (a) E5 parent glass and E5 specimen heated at (b) $600{ }^{\circ} \mathrm{C}$, (c) $650{ }^{\circ} \mathrm{C}$, (d) $700{ }^{\circ} \mathrm{C}$ and (e) $750{ }^{\circ} \mathrm{C}$ for $1 \mathrm{~h}$; excitation spectrum, $\lambda_{\text {ex }}=$ $254 \mathrm{~nm}$. 


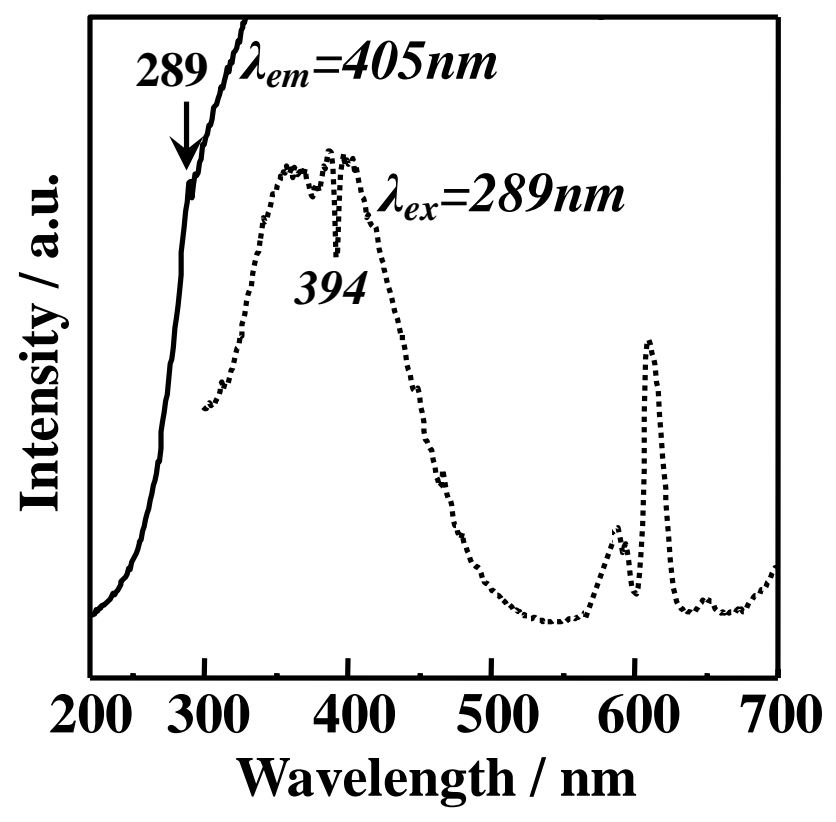

Fig. 8. Excitation (solid line) and emission spectra (dashed line) of E5 parent glass; emission spectrum, $\lambda_{\mathrm{em}}=405 \mathrm{~nm}$; excitation spectrum, $\lambda_{\mathrm{ex}}=289 \mathrm{~nm}$. 


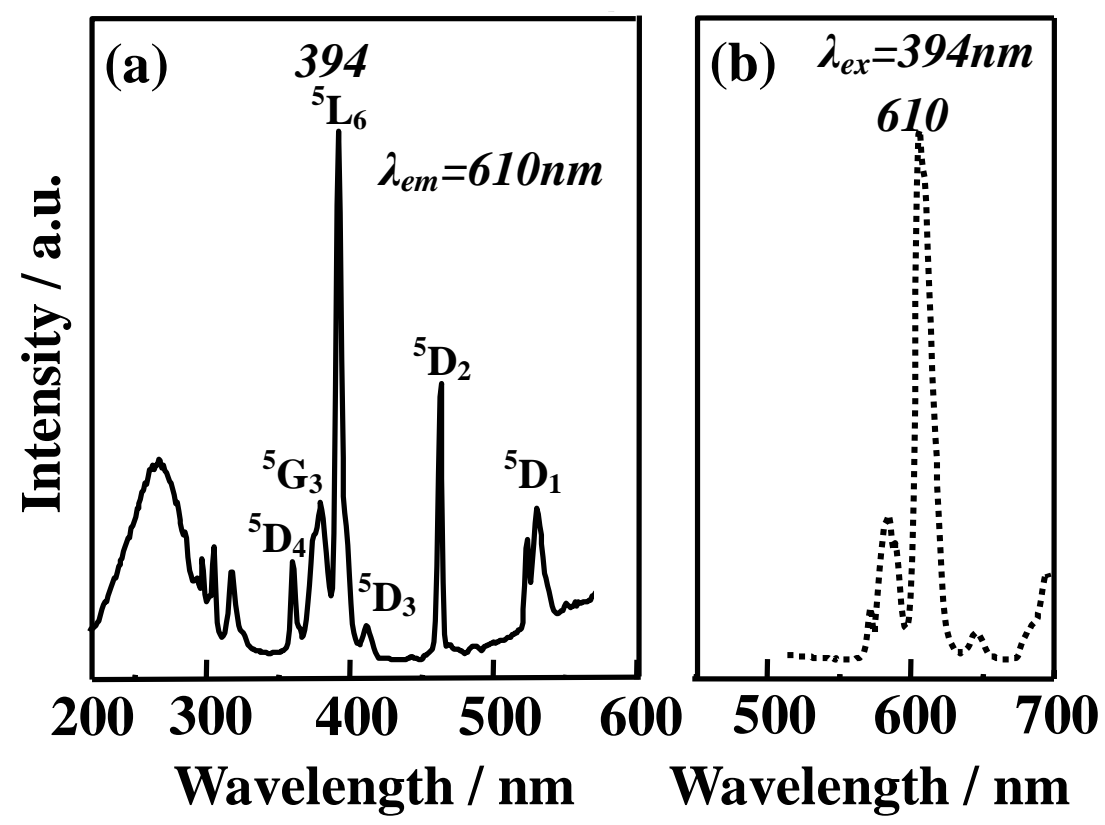

Fig. 9. (a) Excitation and (b) emission spectra of E5 parent glass; emission spectrum, $\lambda_{\mathrm{em}}=610 \mathrm{~nm}$; excitation spectrum, $\lambda_{\mathrm{ex}}=349 \mathrm{~nm}$. 

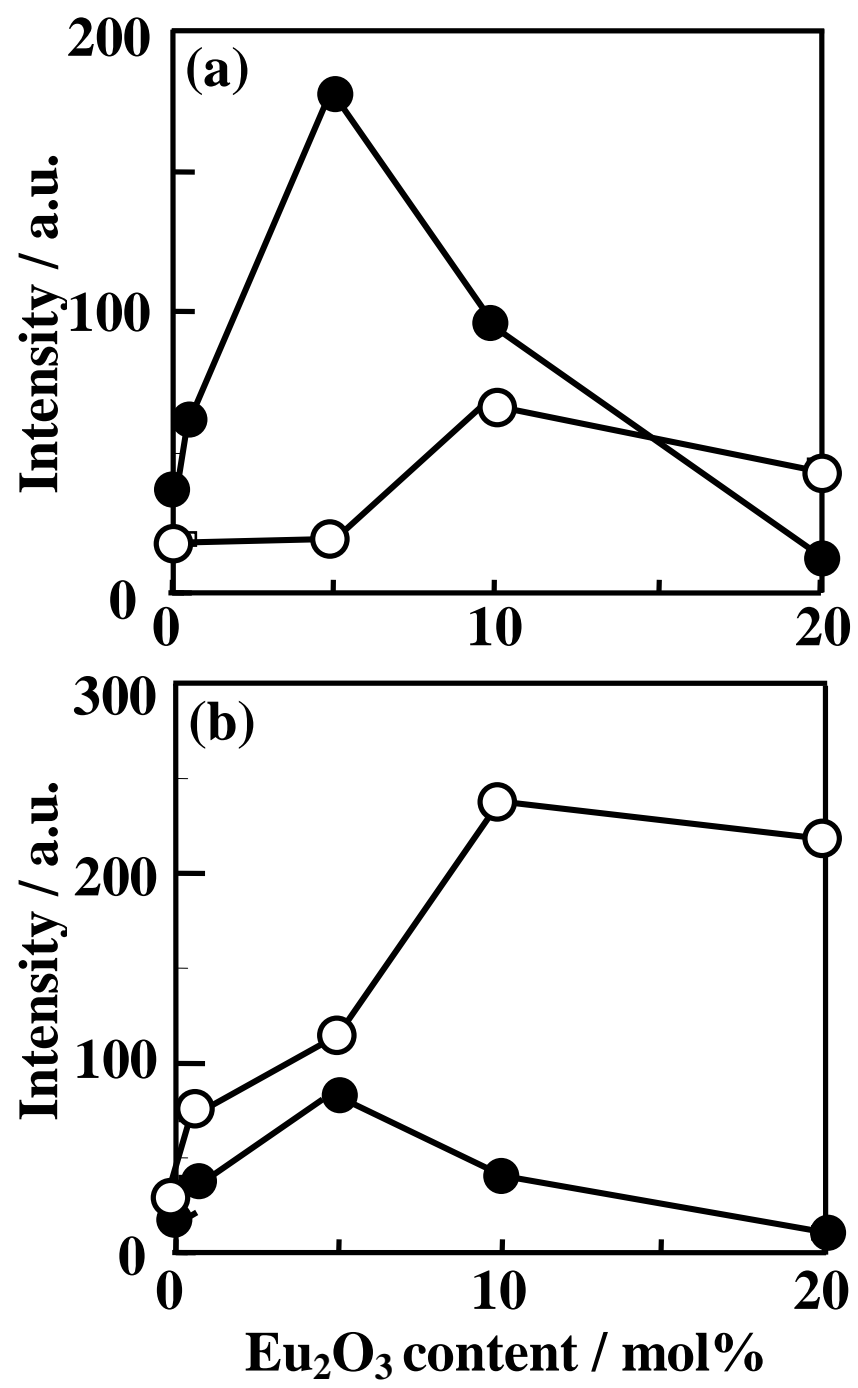

Fig. 10. Changes in emission intensities at (a) $405 \mathrm{~nm}$ and (b) $610 \mathrm{~nm}$ of (o) parent glasses and $(\bullet)$ specimens heated at $700{ }^{\circ} \mathrm{C}$ for $1 \mathrm{~h}$ with an increase in $\mathrm{Eu}_{2} \mathrm{O}_{3}$ content; excitation spectrum, $\lambda_{\mathrm{ex}}=254 \mathrm{~nm}$. 